\title{
Evaluation on Coupling and Coordinated Development of Tourism, Economy and Environment in Yining City, Xinjiang
}

\author{
Donghong Wang \\ Department of Economic and Tourism Management, Xinjiang Applied Vocational Technical College, \\ Kuitun Xinjiang, 833200, China
}

Key words: Yining City, Tourism, Economy and ecological environment, Coordinated development, Evaluation.

\begin{abstract}
According to analysis, coupling and coordinated development level of tourism, economy and environment in Yining City has presented a trend of fluctuated rise over the recent 10 years and has the potential of further improvement. Currently, main problems faced by Yining City are still tourism and economic development problems. However, environmental protection and pollution control cannot be neglected. Coupling and coordinated development of environmental protection, tourism and economic development should be highlighted.
\end{abstract}

\section{Introduction}

With the acceleration of urbanization process, the realization of coordinated development of urban tourism, economy and ecological environment is good for improving urbanization construction quality and promoting coordinated development of social economy. Scholars have conducted relevant study on their coordination state. For example, Wang Yuming ${ }^{[1]}$ and Zhang Yan ${ }^{[2]}$ respectively discussed connotations of coordinated development of tourist economy and ecological environment. Zhang Yuping et al. ${ }^{[3]}$ studied the degree of coupling and coordination of tourism, economy and ecological environment in Turpan area with principal component analysis.

Domestic studies mostly center in regions with developed tourism and economy in China. There are few researches in western small and medium-sized cities. In recent years, Yining City has enhanced the adjustment of economic structure and made efforts to improve urban capacity and development potential. In view of this, this paper studies the status of coordinated development of tourism, economy and ecological environment and provides decision-making reference for coordinated development in Yining City.

\section{Material and research method}

\section{Research area overview and data source}

Yining City has been rated as excellent tourism city, garden city and famous historic city in China. It is also an important traffic hob, tourist distributing center and recreational tourism center city on the economic belt of the Silk Road. Considering the reliability and authority of data, data on national economic and social development statistical bulletin and environmental bulletin of Yining City from 2004 to 2013 are used as basis.

\section{Research method}

Indicator system

This paper establishes an evaluation indicator system of tourism, economy and ecological environment in Yining. Tourism evaluation indicator system: number of inbound tourists $(00,000$ 
person-time), inbound tourism revenue (00,000 US dollars), number of domestic tourists (00,000 person-time), total tourism revenue (00,000 Yuan), proportion of total tourism revenue in GDP (\%), proportion of tourism production value in tertiary industry (\%), number of travel agencies, number of star-rated hotels; economic evaluation indicator system: per capita GDP (Yuan), proportion of secondary industry in GDP (\%), proportion of tertiary industry in GDP (\%), GDP (hundred million Yuan), local financial revenue per capita (Yuan), proportion of total export-import volume in GDP (\%), gross retail sales of social consumer goods per capita (Yuan), fixed assets investment volume per capita (Yuan); ecological environment evaluation indicator system: green area coverage rate of built-up area (\%), volume of wastewater discharge up to the standard $(00,000 \mathrm{t})$, comprehensive utilization ratio of industrial solid wastes (\%), domestic sewage treatment rate of urban residents (\%), industrial soot emission $(\mathrm{t})$, industrial sulfur dioxide emission $(\mathrm{t})$, innocent treatment rate of domestic waste (\%), total area of regions with environmental noise up to the standard $\left(\mathrm{km}^{2}\right)$ and proportion of environmental protection input in GDP (\%).

Indicators are screened with variation coefficient method. Computational formula is $c_{v}=s / x^{\prime}$, where $S$ refers to sample variance and $x^{\prime}$ refers to average value of each indicator.

Standardized value $x_{i j}^{\prime}$ of the selected indicator is calculated with efficacy function method. Formula: Positive indicator: $\quad x_{i j}{ }^{\prime}=\left[x_{i j}-\min \left(x_{j}\right)\right] /\left[\max \left(x_{j}\right)-\min \left(x_{j}\right)\right]$, negative indicator: $x_{i j}^{\prime}=\left[\max \left(x_{j}\right)-x_{i j}\right] /\left[\max \left(x_{j}\right)-\min \left(x_{j}\right)\right]$

Where $x_{i j}$ refers to the original value of the selected indicator; $\min \left(x_{j}\right)$ and $\max \left(x_{j}\right)$ respectively refer to upper and lower limits of the indicator.

This paper determines the weight of each indicator with improved entropy method. Entropy is $e_{j}=-\frac{1}{\ln m} \sum_{i=1}^{m}\left(y_{i j} \ln y_{i j}\right), e_{j} \in[0,1]$

Where, $y_{i j}=\left(1+x_{i j}{ }^{\prime}\right) / \sum_{i=1}^{m}\left(1+x_{i j}{ }^{\prime}\right)$. Weight formula: $w_{j}=\left(1-e_{j}\right) / \sum_{j=1}^{n}\left(1-e_{j}\right)$

Comprehensive benefits of tourism industry, economy and ecological environment are calculated with linear weighting method. Formula: $u_{i}=\sum_{j=1}^{m} w_{j} x_{i j}{ }^{\prime}$

Their interactive coupling degree and coupling coordination degree are calculated with coupling degree function and coupling coordination degree function ${ }^{[3]}$. Formula: $C=\frac{3 \sqrt[3]{u_{1} \times u_{2} \times u_{3}}}{u_{1}+u_{2}+u_{3}}$, where $C$ refers to the coupling degree of the three systems and $\mathrm{u}_{1}, \mathrm{u}_{2}$ and $\mathrm{u}_{3}$ respectively refer to comprehensive benefits of tourism industry, economy and ecological environment.

To evaluate their coupling coordination degree better, coupling coordination degree function is used. Formula:

$\left\{\begin{array}{l}D=\sqrt{C \times T} \\ T=\alpha u_{1}+\beta u_{2}+\delta u_{3}\end{array}\right.$

Where, $\mathrm{D}$ refers to coupling coordination degree; $\mathrm{C}$ refers to coupling degree; $\mathrm{T}$ is comprehensive evaluation index of the three systems; $\alpha, \beta$ and ${ }^{\delta}$ refer to weight to be determined. According to their influence level in interaction, $\alpha=0.35, \beta=0.3, \delta=0.35$.

Coupling coordination degree is divided into 10 grade standards with uniform distribution function method: $0 \leqslant \mathrm{D} \leqslant 0.09$, extreme imbalance; $0.1 \leqslant \mathrm{D} \leqslant 0.19$, serious imbalance; $0.2 \leqslant \mathrm{D} \leqslant 0.29$, moderate imbalance; $0.3 \leqslant \mathrm{D} \leqslant 0.39$, mild imbalance; $0.4 \leqslant \mathrm{D} \leqslant 0.49$, close to imbalance; $0.5 \leqslant \mathrm{D} \leqslant$ 0.59 , strained imbalance; $0.6 \leqslant \mathrm{D} \leqslant 0.69$, primary coordination; $0.7 \leqslant \mathrm{D} \leqslant 0.79$, intermediate coordination; $0.8 \leqslant \mathrm{D} \leqslant 0.89$, good coordination; $0.9 \leqslant \mathrm{D} \leqslant 1$, high-quality coordination.

\section{Result and analysis}


Coupling degree and coupling coordination degree are calculated with the research method above. See table 1.

\section{Comprehensive benefit evaluation analysis}

According to table 1, comprehensive benefit of tourism in Yining presented a trend of steady growth in other years except reduction in 2008-2009; comprehensive index of economic benefit presented a trend of fast growth in other years except slow development speed in 2009 and economic development momentum is good; comprehensive benefit of ecological environment presented a trend of growth in other years except fluctuation in 2007 and 2009.

Since 2011, Yining has accelerated the transformation and upgrading of tourism industry, adjusted economic structure, established and improved ecological environmental protection management system, protected the integrity and important ecological place, maintained and improved functions of ecological environment, protected ecological environment through strict measures and strengthened the control over environmental influence caused by accelerated development of urbanization and natural disasters. According to comparative analysis, the development of tourism, economy and environment in Yining has been promoted by relevant policies of the local government and made great progress. Therefore, to improve the overall coordinated development level of Yining, it is required to accelerate tourism and economic development and meanwhile strengthen environmental construction investment. Tourism and economic development must be within the scope of carrying capacity of ecological environment.

Table 1 Evaluation value of tourism, economy and ecological environment in Yining

\begin{tabular}{|c|c|c|c|c|c|c|c|}
\hline Year & U1 & U2 & U3 & C & T & D & Coordination grade \\
\hline 2004 & 0.031 & 0.078 & 0.186 & 0.770 & 0.099 & 0.276 & Moderate imbalance \\
\hline 2005 & 0.097 & 0.156 & 0.296 & 0.898 & 0.184 & 0.407 & Close to imbalance \\
\hline 2006 & 0.217 & 0.156 & 0.467 & 0.896 & 0.286 & 0.506 & Strained coordination \\
\hline 2007 & 0.352 & 0.249 & 0.363 & 0.986 & 0.325 & 0.566 & Strained coordination \\
\hline 2008 & 0.325 & 0.369 & 0.558 & 0.972 & 0.420 & 0.639 & Primary coordination \\
\hline 2009 & 0.271 & 0.389 & 0.562 & 0.957 & 0.408 & 0.624 & Primary coordination \\
\hline 2010 & 0.503 & 0.470 & 0.641 & 0.991 & 0.541 & 0.732 & Intermediate coordination \\
\hline 2011 & 0.657 & 0.509 & 0.656 & 0.993 & 0.614 & 0.780 & Intermediate coordination \\
\hline 2012 & 0.758 & 0.533 & 0.675 & 0.990 & 0.661 & 0.809 & Good coordination \\
\hline 2013 & 0.882 & 0.769 & 0.715 & 0.996 & 0.789 & 0.887 & Good coordination \\
\hline
\end{tabular}

\section{Analysis on coupling degree and coupling coordination degree}

According to table 1, the coupling degree of tourism, economy and ecological environment in Yining generally rose steadily from 0.77 in 2004 to 0.996 in 2013 though there was some fluctuation. Coupling coordination degree rose steadily in other years, from 0.276 in 2004 to 0.887 in 2013, except slight fluctuation in 2009.Their comprehensive evaluation index presented a trend of steady rise in other years except reduction in 2009 over the recent 10 years. Their overall cooperative contributions have constantly increased. Their comprehensive benefits generally developed towards the same direction.

Their coordinated development grade changed to good coordination from the original moderate imbalance. However, comprehensive evaluation index of tourism and economy was obviously faster than that of ecological environment after 2011. The rapid development of tourism and economy produced great influence on the protection and control of ecological environment. This will restrict their coupling degree and coupling coordination degree. Therefore, keeping their sustainable development is an important foundation of coupling and coordinated development.

\section{Analysis on coupling coordination type}


According to table 1, their coupling coordination degree type gradually changed to leading development of tourism from leading development of economy and from moderate imbalance stage to good coordination stage gradually. Tourism industry has become the strategic pillar industry of economic development in Yining. The sustainable development of tourism industry has driven economic development and environmental protection. However, if the development of tourism and economy exceeds the intensity of ecological environmental protection, they will have certain conflicts with the threshold value of ecological environment system. Their uncoordinated development will cause their imbalance and restrict the sustainable development of the region to a certain extent.

\section{Conclusion}

According to the study on coupling and coordinated development situation of tourism, economy and environment in Yining, the result basically meets the objective reality. As tourism, economy and ecological environment have complicated coupling interaction and tourism and economic development has comprehensive benefits in the initial stage of urban tourism and economic development, they have small environmental influence and the three systems have a low-level coupling coordination degree. The development of tourism and economy provides solid guarantee for the protection of ecological environment. Their incoordination state will gradually weaken and a high-level coupling coordination degree will form gradually.

According to the analysis on comprehensive benefits, tourism industry is the pillar industry of economic development in Yining. However, tourism industry is easily affected by emergency. Emergency has greater adverse influence on tourism industry than favorable influence. Therefore, it has great fluctuation. After the occurrence of emergency, local government should establish emergency response mechanism so as to adapt to and adjust the negative influence of emergency and improve the ability of emergency disposal of emergency and risk resistance of tourism industry. Meanwhile, with economic development, the government has taken strict measures for environmental protection and conducted publicity and education, improved the awareness of unexpected development and crisis awareness of the society for environmental protection, thus allowing certain development of ecological environmental protection in Yining. This indicates that only with high stability, equilibrium and taste can ecological environmental system has strong market competitiveness so as to lay foundation for the improvement of tourism and economic development. To keep their coordinated development, it is also necessary to enhance economic, education, administrative and legal means for scientific management over ecological environment.

In terms of coupling degree and coupling coordination degree, coupling coordination degree is high. The main reason is that tourism and economic development is slow in Yining and its comprehensive benefit is relatively low. Environmental influence is controlled within certain threshold scope. The development of tourism and economy provides certain material support for the protection of ecological environment. Currently, main problems faced by Yining City are still tourism and economic development problems. However, environmental protection and pollution control should be enhanced. The coexistence of ecological environmental protection, tourism and economic development and coupling and coordinated development and sustainable development of ecological environment and tourism and economy should be highlighted.

\section{Acknowledgement}

College Scientific Research Plan Program of Xinjiang Uygur Autonomous Region, No.: XJEDU2014S089 .

Scientific Research Plan Program of Xinjiang Vocational Education Institute, No.: XJZJXH2014-18. 


\section{References}

[1] Wang Yuming, Zhao Zhonghua. Study on Tourism Capacity and Carrying Capacity of Metropolis Based on Shanghai Case, China Population Resources and Environment, 2007, 17(5):118-122.

[2] Zhang Yan, Xu Jianhua, Zeng Gang et al. Establishment of Evaluation Model of Sustainable and Coordinated Development of Tourism - Economy - Ecological System and Empirical Study Take Guilin, Guangxi for Example, Tourism Science, 2008, 22(3):31-35.

[3] Zhang Yuping, Wahap, Holek, Dang Jianhua et al. Analysis on Coupling and Coordinated Development of Turpan Tourism - Economy - Ecological Environment, Human Geography, 2014(4):140-145. 